\title{
Simulations and Experiments on Vibration Control of Aerospace Thin-Walled Parts via Preload
}

\author{
Qiong Wu, Lei Li, and Yi-Du Zhang \\ State Key Laboratory of Virtual Reality Technology and Systems, School of Mechanical Engineering and Automation, \\ Beijing University of Aeronautics and Astronautics, Beijing 100191, China
}

Correspondence should be addressed to Yi-Du Zhang; ydzhangbuaa@126.com

Received 6 September 2017; Revised 21 November 2017; Accepted 29 November 2017; Published 17 December 2017

Academic Editor: Giosuè Boscato

Copyright (C) 2017 Qiong Wu et al. This is an open access article distributed under the Creative Commons Attribution License, which permits unrestricted use, distribution, and reproduction in any medium, provided the original work is properly cited.

Thin-walled parts primarily comprise the entire piece of rough machining, and the material removal rate can surpass $95 \%$. Numerous components with thin-walled structures are preferred in the aerospace industry for their light weight, high strength, and other advantages. In aerospace thin-walled workpiece machining processes and practical applications, they are excited by the vibration. The preload changing the modal stiffness of the part is found and this change causes continuous changes in the natural frequency. Researching on the influence of pretightening force on dynamic characteristics of thin-walled components is highly significant for controlling vibration. In this study, the typical aviation thin-walled part is the research object. Finite element numerical simulation and experimental verification are employed to analyze the dynamic characteristics of 7075 aluminum alloy thin-walled plates under different preloads for exploring the relationship between natural frequency and preload. The relationship is validated by comparative results. Both the simulation and experimental results show that the natural frequencies of plates increase following the augmentation of the preload. Thus, this research introduces the method where vibration of aerospace thin-walled parts is reduced by preload. For practical engineering application, a program showing the relationship between natural frequency and preload is written using Visual Basic language.

\section{Introduction}

With higher performance requirements of aircraft and spacecrafts, the monolithic components are extensively applied in aerospace industry. The aviation monolithic components are in the possession of many advantages such as lower height, higher assembly quality, and higher structural efficiency. However, these components are large in size, complex in structure, and often thin-walled [1-4]. The thin-walled structures flexibly induce higher amplitude oscillations by any disturbance. This phenomenon could result in malfunctions in application and machining process. Vibration, a classical phenomenon, indicates operating accuracy and stability of the structures, and long-term vibration may cause fatigue damage to the structures and reduce their service life [5-11].

Given the importance of vibration, scholars analyzed the vibration of structures and explored various control methods. Two different approaches can be taken to solve the vibration problem. The first series of approaches are to make the structure stiffer or add damping in proper locations [1216]. These approaches are called passive vibration control methods. The other methods named active vibration are to suppress the vibration amplitude actively [17-21]. Active approaches are more effective in comparison with passive methods, because the vibration frequency and amplitude are measured in real time, and an accurately calculated reaction force or moment is applied to the structure in active control process. However, some disadvantages exist in applications of these active vibration control methods, such as the required electrical power, size, and price of required sensors and actuators and the limited disturbance rejection range in which the closed-loop system remains stable [22]. Therefore, to explore a simple and reliable engineering method is meaningful.

Many factors affect vibration such as materials, assembly method, surface behaviors, and shape [23-27]. Researchers consider that vibration can be affected by preload in the machining and application processes of aerospace thinwalled parts [28-32]. In engineering practice, dynamic 


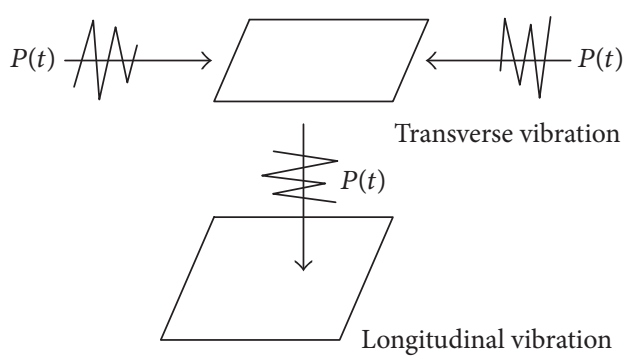

FIGURE 1: Transverse and longitudinal vibrations of a thin-walled plate.

characteristic parameters of the workpieces under different preloads should be considered to analyze the effect of vibration on their functions. Although a series of studies on the dynamic characteristics of preload system have been conducted, research on the dynamic characteristics of thinwalled components under different preloads remains lacking. To fill this gap, this study explores the relationship between the dynamic characteristics of thin-walled aviation workpieces and preload. Thus, the vibration can be controlled by changing the preload within the licensed conditions.

\section{Vibration Analysis of Thin-Walled Plates under Preload}

Two kinds of vibration forms, namely, transverse and longitudinal, are shown in Figure 1. Regarding the vibration forms of thin-walled plates, this study only discusses the transverse vibration because it is an important influencing factor in engineering.

According to Kirchhoff's classical plate theory, the free vibration equation for the lateral motions of a homogeneous, isotropic, linear elastic thin plate is given by

$$
D\left(\frac{\partial^{4} w}{\partial x^{4}}+2 \frac{\partial^{4} w}{\partial x^{2} \partial y^{2}}+\frac{\partial^{4} w}{\partial y^{4}}\right)+\rho h \frac{\partial^{2} w}{\partial t^{2}}=0
$$

Here, $w(x, y, t)$ is the lateral displacement of the plate middle surface, with $x, y$-axes forming the plate plane, and $t$ is the time, $h$ is the thickness, $\rho$ is the mass density, $D=$ $E h^{3} / 12\left(1-\mu^{2}\right)$ is the flexural stiffness, and $E$ and $\mu$ represent the Young modulus and Poisson ratio, respectively [33].

Suppose the principal mode of vibration of a thin plate is $W(x, y)$; then the principal vibration can be written as follows:

$$
w(x, y, t)=W(x, y) \sin (\omega t+\varphi)
$$

where $\omega$ is the natural frequency. When (2) is substituted into (1), the free vibration equation of thin plate can be expressed as follows:

$$
D\left(\frac{\partial^{4} W}{\partial x^{4}}+2 \frac{\partial^{4} W}{\partial x^{2} \partial y^{2}}+\frac{\partial^{4} W}{\partial y^{4}}\right)-\rho h \omega^{2} W=0
$$

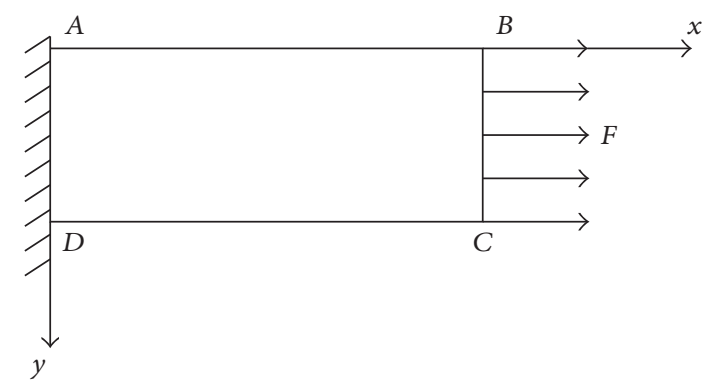

Figure 2: Boundary conditions of a plate.

TABle 1: Physical parameters of aluminum alloy 7075.

\begin{tabular}{lcccc}
\hline Properties & $\begin{array}{c}\text { Young's } \\
\text { modulus/GPa }\end{array}$ & $\begin{array}{c}\text { Poisson's } \\
\text { ratio }\end{array}$ & Density $/ \mathrm{kg} \cdot \mathrm{m}^{3}$ & $\begin{array}{c}\text { Yield } \\
\text { strength/MPa }\end{array}$ \\
\hline Value & 75 & 0.33 & 2700 & 375 \\
\hline
\end{tabular}

Setting $\partial^{4} W / \partial x^{4}+2\left(\partial^{4} W / \partial x^{2} \partial y^{2}\right)+\partial^{4} W / \partial y^{4}=\nabla^{4} W$, the natural frequency can be obtained as

$$
\omega=\sqrt{\frac{D}{\rho h}} \sqrt{\frac{\nabla^{4} W}{W}}
$$

The main vibration mode $W(x, y)$ depends on the boundary conditions, as the plate is fixed. The boundary conditions of the rectangular plate under the preload parallel to the middle surface direction are shown in Figure 2. One side of the plate is fixed, and another side suffers from preload $F$.

At present, calculating the natural frequencies of thinwalled plates under certain preloads is very difficult. Different constraint conditions and systems have their natural frequencies that are difficult to calculate and solve precisely. Therefore, we only discuss the influence of preload on natural frequency. The particular corresponding relation of them is needed to explore employing following simulation and experimental methods.

\section{Solution for Thin-Walled Plates Using FEM}

Aluminum alloys possess many advantages, such as small density, high strength, high corrosion resistance, high formability, and low cost. In the aviation, aerospace, shipbuilding, nuclear and arms industries, and aluminum alloys possess extensive application prospects and an irreplaceable status. Aluminum alloy 7075 widely used by aerospace field is a kind of superhard alloy that possesses an impressive comprehensive performance. Aluminum alloy 7075T7351 plates are used in this research. Their physical specifications are listed in Table 1, and their dimensions are $150 \times 50 \times 0.5 \mathrm{~mm}$.

The FEM providing approximate solution to a modal problem is a powerful tool for assessing the potential variations caused by preload on thin plates. The FEM software ANSYS is applied to measure the natural frequency of the plates under different preloads. 


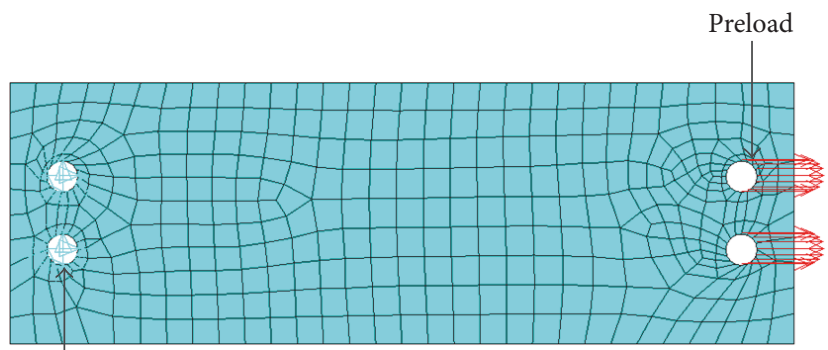

Constraint

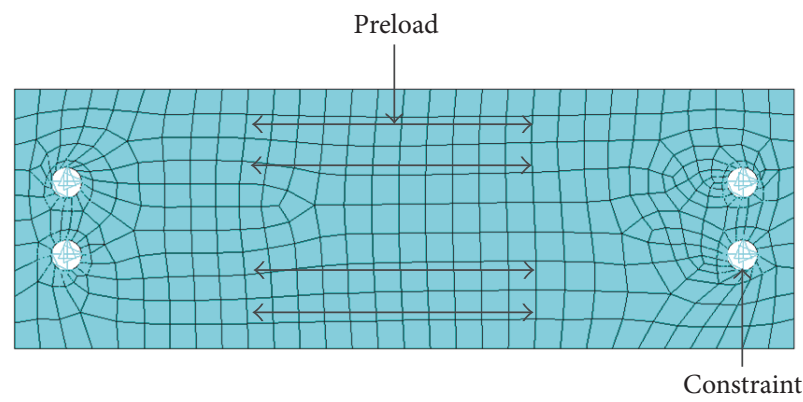

(b)

FIgURE 3: ANSYS simulation model of thin plates. (a) Loading simulation. (b) Dynamics simulation.

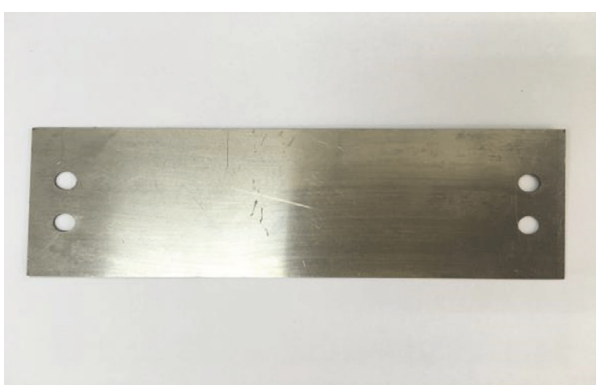

(a)

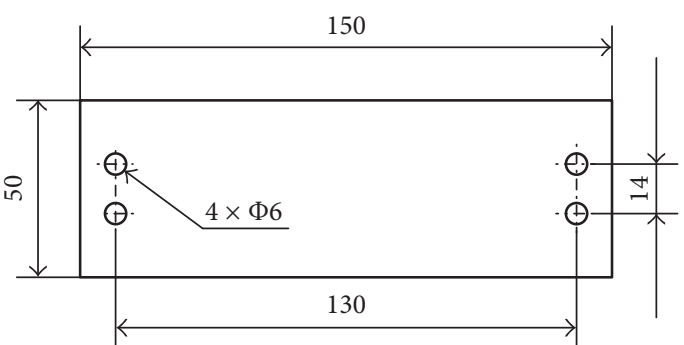

(b)

Figure 4: (a) Specimen. (b) Size and structure of specimen.

In the simulation, the isotropic thin plate with a preload is replaced with the model whose one side is under displacement constraint from all directions and whose other side suffers from certain size pressure representing the size of the preload, as shown in Figure 3(a). After applying the preload, force occurs in the thin-walled plate because of the preload. In dynamics simulation, two sides of the model are under displacement constraints, and the force obtained from the pressure is exerted on the plate, as depicted in Figure 3(b). The holes in the picture are used to fix and load simulation plates. Considering the influence of preload, modal analysis is performed on the basis of this model. We obtain the natural frequency and vibration mode under different preloads.

The finite element simulation analyzes thin plates under different preloads from 0 to $100 \mathrm{~N}$, and $10 \mathrm{~N}$ is the increase gradient value of force. Each case analyzes the natural frequencies and vibration modes of the first four orders. The results of simulation are discussed in the following section.

\section{Analyses of Experimental and Simulation Results}

The material of thin-walled part used in this experiment is 7075 aluminum alloy. The size and structure of the specimens are shown in Figure 4. The holes are used to fix and load experimental specimens. The material parameters of experimental plates are listed in Table 1.

The comprehensive experiment platform is independently machined and assembled by us. It includes a control system and a loading system as described in Figure 5(a). The scanning laser vibrometer is used to measure vibration of thin aluminum alloy plates. The experiment platform and vibrometer are shown in Figure 5(b).

The specific experimental steps are as follows:

(1) The experimental apparatus includes experimental equipment of MCU development, a two-phase hybrid stepper motor drive, a stepper motor, and an intelligent controller. We set the instrument and adjust parameters to ensure that all the instruments function properly and that the control system can effectively control step motor rotation.

(2) A scanning laser vibrometer is installed using the manual, and a fixed tripod of the laser scanning head is adjusted to position the laser perpendicular to the thinwalled board, as described in Figure 5(b). This step is especially important.

(3) The thin plate is installed and fixed on the experimental platform, and the initial preload of the plate is $0 \mathrm{~N}$.

(4) Through positive and negative buttons on the MCU development board, a stepping motor is controlled to exert different sizes of preload for thin-walled parts from 0 to $100 \mathrm{~N}$, and a force of $10 \mathrm{~N}$ is added every time.

(5) By exciting the thin plate with an elastic force hammer, the dynamic characteristic parameters of thin-walled workpieces are obtained using control and analysis software PSV500.

(6) Replacing the thin plate, steps (3) to (5) are repeated. 11 groups of data are received. Data contain the natural frequencies of the first four orders in each group. 


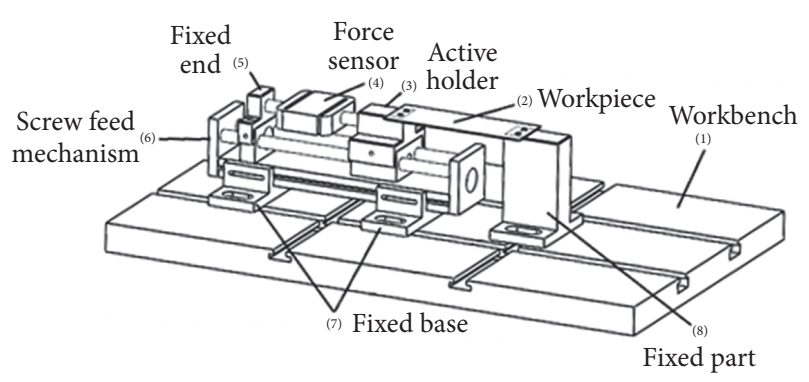

(a)

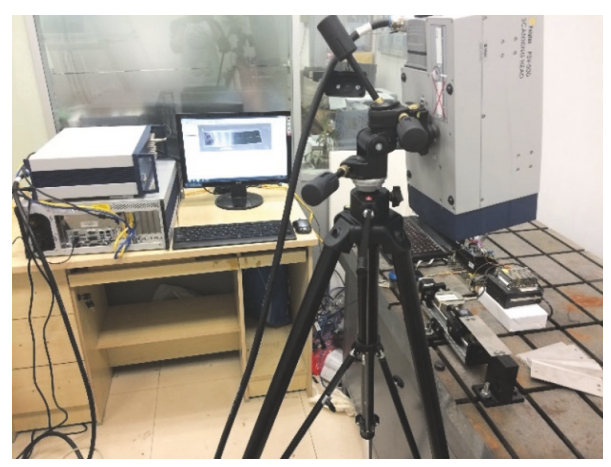

(b)

Figure 5: (a) Comprehensive experiment platform. (b) Comprehensive test experiment platform and scanning laser vibrometer.

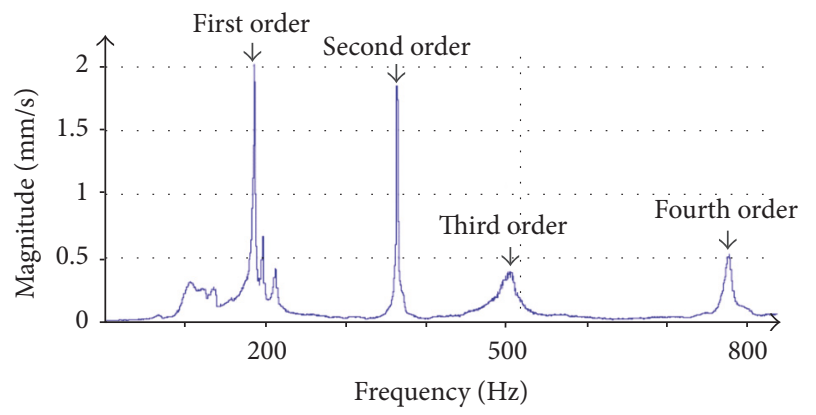

FIGURE 6: Experimental natural frequency of first four orders of thin-walled plates under a $50 \mathrm{~N}$ preload.

TABLE 2: Average error of the natural frequency values of the first four orders from simulation and experiment.

\begin{tabular}{lcccc}
\hline $\begin{array}{l}\text { Natural } \\
\text { frequency order }\end{array}$ & $\begin{array}{c}\text { The first } \\
\text { order }\end{array}$ & $\begin{array}{c}\text { The second } \\
\text { order }\end{array}$ & $\begin{array}{c}\text { The third } \\
\text { order }\end{array}$ & $\begin{array}{c}\text { The fourth } \\
\text { order }\end{array}$ \\
\hline Average error & $2.9 \%$ & $1.9 \%$ & $0.9 \%$ & $0.4 \%$ \\
\hline
\end{tabular}

The dynamic characteristic parameters of the thin-walled part under preload $F=50 \mathrm{~N}$ are measured using a comprehensive test experiment platform and a scanning laser vibrometer (Figure 6).

The average error of the natural frequency values of the first four orders obtained from the simulation and experiment is expressed in Table 2. All the average error values of natural frequency are small and the largest value is only $2.9 \%$. All of the average error values fall within the acceptable range in engineering.

To intuitively show the distinction between the simulation and experiment, contrast curves of the first four orders of the simulation and experiment are compared, in Figure 7. Based on the shape of the curves, both the simulation and experiment show that the natural frequencies of thin plates increase following the augmentation of the preload. As described in the curve graphs, the change of the natural frequency from experiments is more apparent than that in simulations; nevertheless, they all increase. The shapes of the simulation curves are approximately linear and more regular. The experiment curves are relatively discrete, but the curves of the experiment and simulation values are extremely close. When preload is from $0 \mathrm{~N}$ to $100 \mathrm{~N}$, the maximal variation of natural frequency is $42.2 \mathrm{~Hz}$ at third-order experimental status. All curves indicate that the experiment values are greater than the simulation values. This situation is realistic.

Equation (4) shows influence factors of natural frequency. Boundary conditions can affect the main vibration mode of thin-walled plate, and change of preload can alter the $W(x, y)$ to get different frequencies. However, the mathematical expression of $W(x, y)$ almost can not be calculated in detail, so we interpreted it from another perspective. Assuming that boundary conditions are invariable, increase of $F$ is equal to the augment of stiffness for lateral vibration of plate and main vibration mode is fixed. That is to say, it leads to augmentation of elasticity modulus $E$. According to $D=E h^{3} / 12\left(1-\mu^{2}\right)$ and (4), the increase of $F$ enlarges the natural frequency of thinwalled plate.

When the plates undergo a preload $F=50 \mathrm{~N}$, the vibration modes obtained through simulation and experiment are similar (Figure 8).

Given the aforementioned simulation and experiment research for thin plates with different preloads, natural frequencies can be estimated by writing a program. The interface is exhibited in Figure 9. The software is used to calculate the natural frequency of the thin-walled plate under different preloads. This is important reference to control the natural frequency to reduce vibration in employing and manufacturing of aerospace thin-walled components. Natural frequency values and vibration mode graphics of the first six orders are provided in the picture.

A easy and practical engineering method controlling vibration is found. Severe vibration occurs when the forcing frequency is equal to natural frequency. The machining process of thin-walled workpieces and the practical application are influenced by the vibration. Changing the preload varies the stiffness and it causes the natural frequency of the system to change continuously. Resonance frequency of system is changed and vibration of aviation thin-walled parts is reduced via adjusting preload within effective range. 


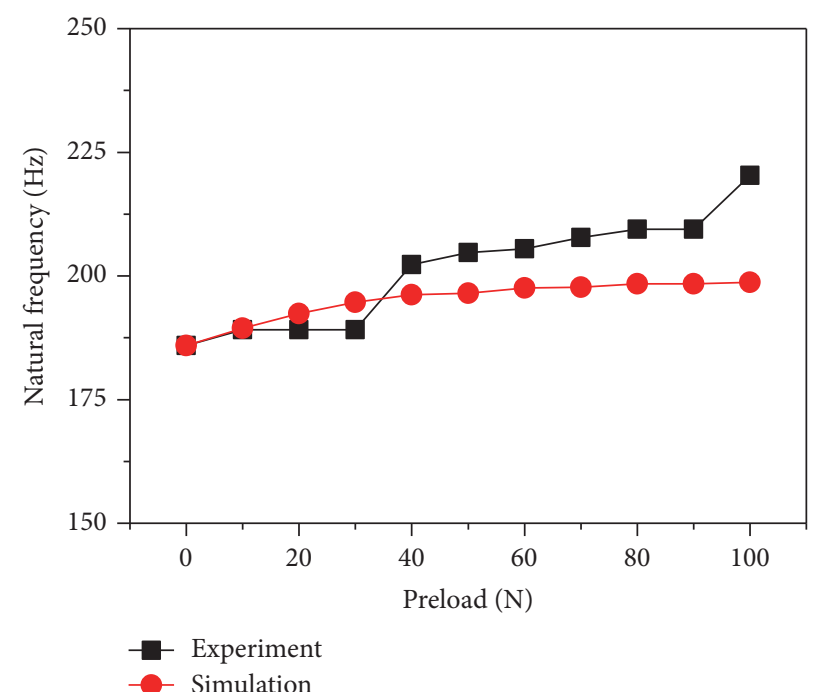

(a)

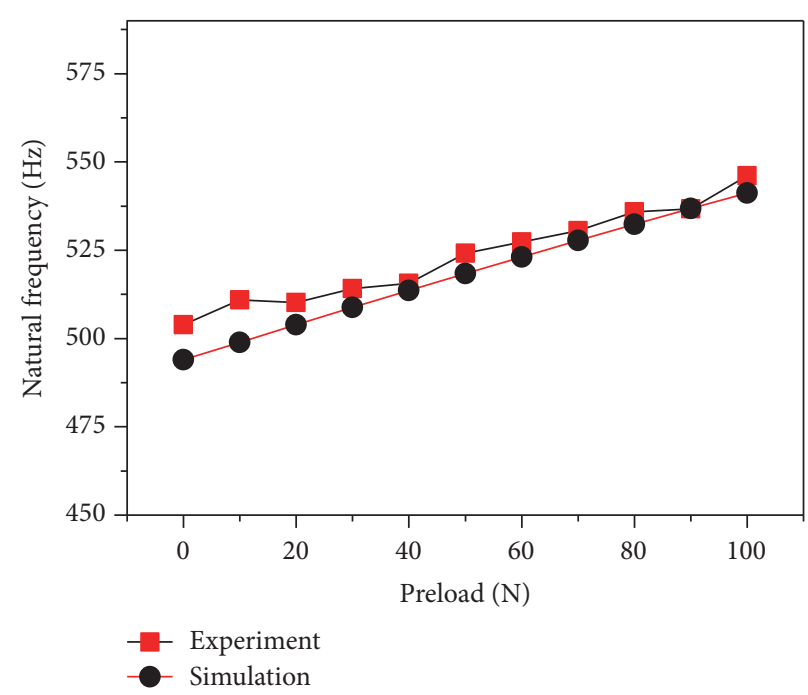

(c)

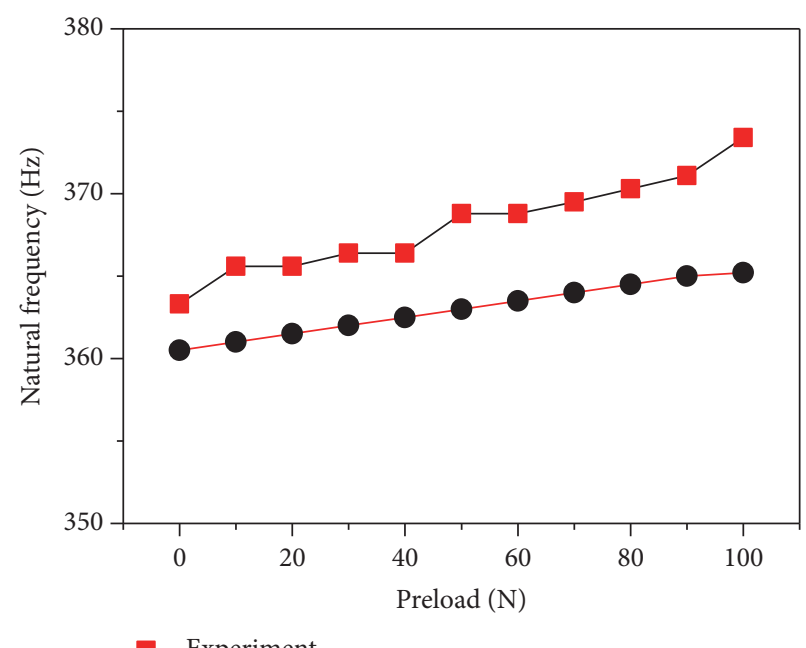

Experiment

Simulation

(b)

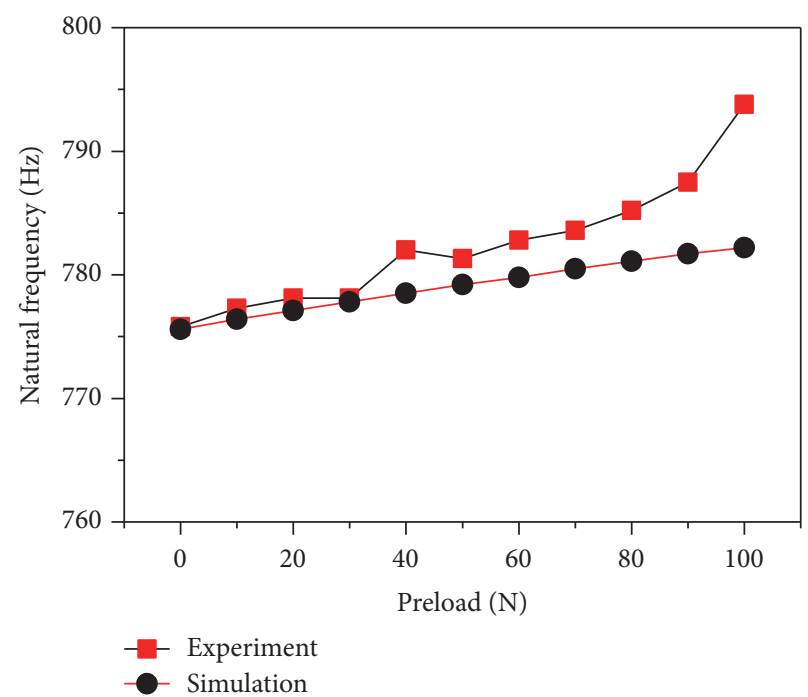

(d)

FIGURE 7: Contrast curves of simulation and experimental values of the natural frequency of the first four orders. (a) First-order natural frequency. (b) Second-order natural frequency. (c) Third-order natural frequency. (d) Fourth-order natural frequency.

\section{Conclusions}

(1) The finite element simulation analysis of the dynamic characteristics of thin plates under pretightening force includes a 3D model and modal analysis simulation. Through simulation, the relationship between preload and modal parameters, such as natural frequency and vibration mode, is obtained.

(2) Comprehensive experiment platform used to measure dynamic characteristics of aviation thin-walled parts under a certain preload is designed, and experimental modal analysis of the parts is carried out. The law that natural frequency increases with increasing preload is summarized based on analysis of the numerical solutions and experimental solutions of the dynamic characteristics.
(3) According to the results of simulation and experiment, resizing preload to change the natural frequency of parts is a highly effective approach to avoid strong vibration of aerospace thin-walled workpieces.

(4) On the basis of the finite element software ANSYS, computing system of dynamic characteristic parameters of thin-walled components under preload is developed adopting object-oriented development language. This software simplifies treatment processes of finite element analysis, shortens the analysis time, achieves parametric modeling, and improves efficiency.

\section{Conflicts of Interest}

The authors declare that there are no conflicts of interest. 


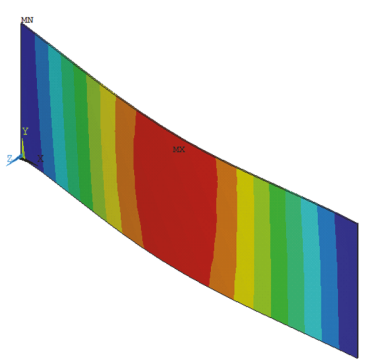

(a) Simulation and experiment

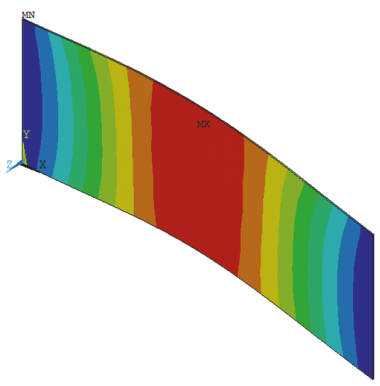

(c) Simulation and experiment
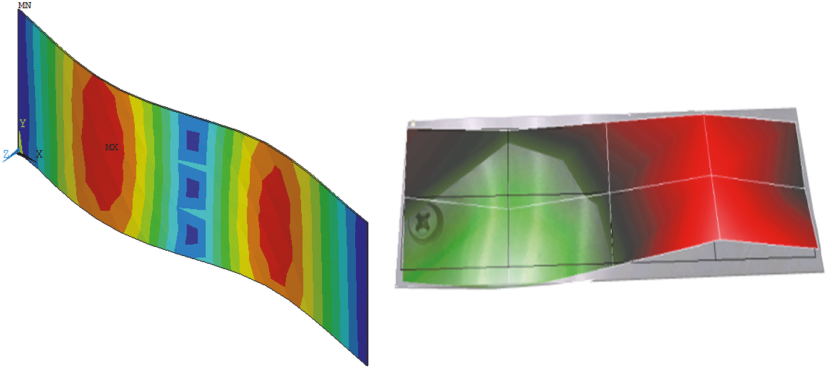

(b) Simulation and experiment
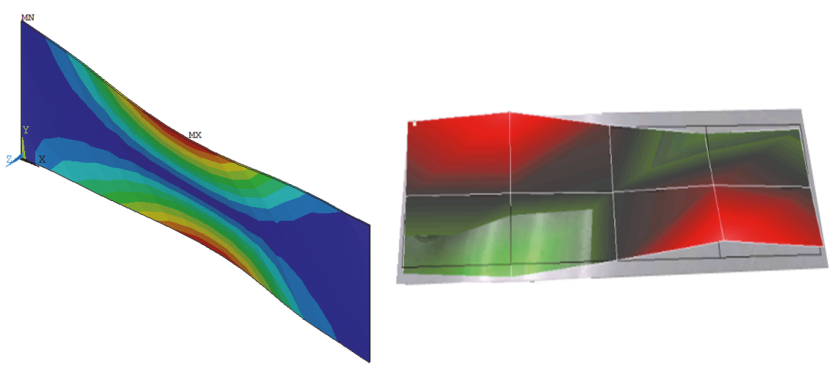

(d) Simulation and experiment

Figure 8: Contrast graphs of simulation and experiment values of the vibration mode of the first four orders. (a) The first-order vibration mode. (b) The second-order vibration mode. (c) The third-order vibration mode. (d) The fourth-order vibration mode.

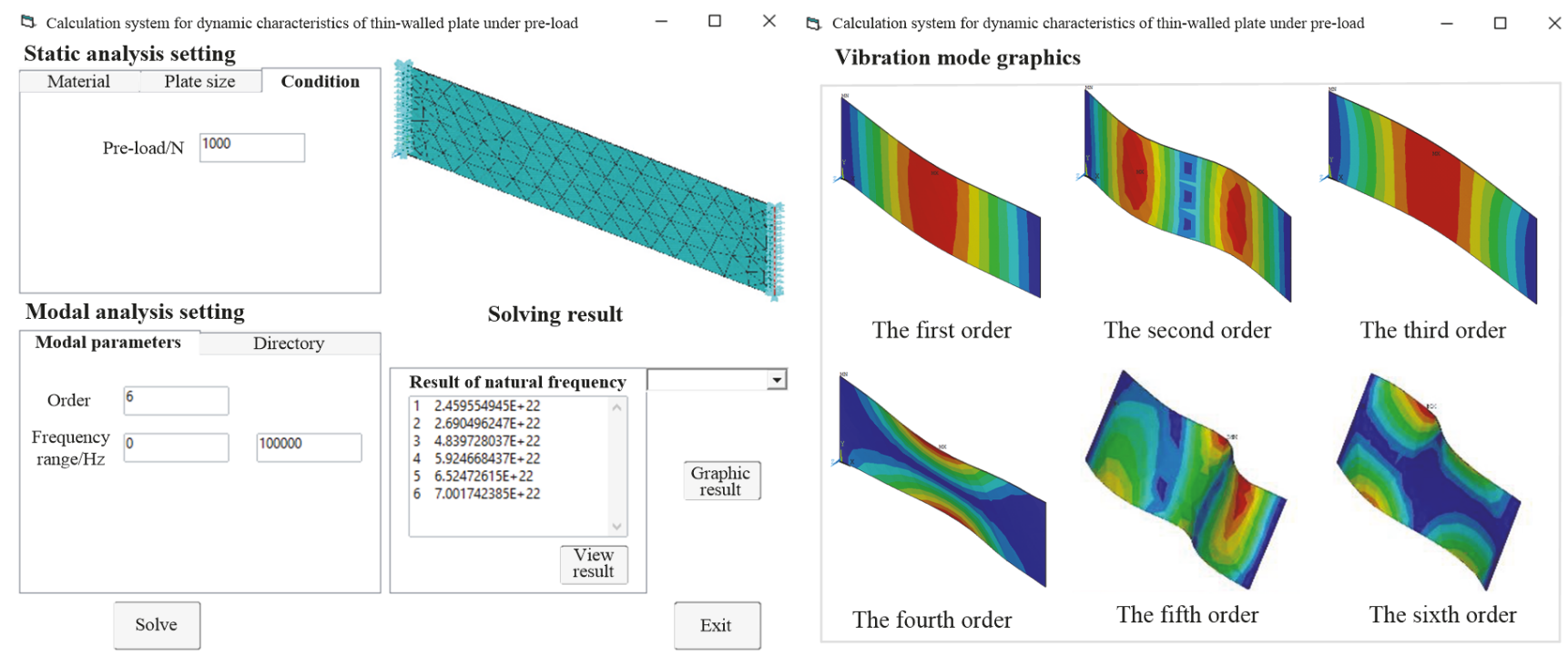

FIGURE 9: Screenshot of the program and calculation results.

\section{Authors' Contributions}

Qiong Wu, Lei Li, and Yi-Du Zhang conceived and designed the experiments; Qiong Wu and Lei Li performed the experiments; Qiong Wu and Lei Li analyzed the data; Qiong Wu and Lei Li wrote the paper.

\section{Acknowledgments}

This work was supported by the National Science and Technology Major Project (Grant no. 2014ZX04001011), Defense
Industrial Technology Development Program (Grant no. A0520110009), and Beijing Municipal Natural Science Foundation (Grant no. 3172021).

\section{References}

[1] R. Izamshah, J. P. T. Mo, and S. Ding, "Hybrid deflection prediction on machining thin-wall monolithic aerospace components," Proceedings of the Institution of Mechanical Engineers, Part B: Journal of Engineering Manufacture, vol. 226, no. 4, pp. 592-605, 2012. 
[2] I. Raja, "Deflection prediction on machining thin-walled monolithic aerospace component," Proceedings of the Institution of Mechanical Engineers, Part B: Journal of Engineering Manufacture, vol. 226, no. 4, pp. 592-605, 2011.

[3] Q. Wu and D.-P. Li, "Analysis and X-ray measurements of cutting residual stresses in 7075 aluminum alloy in high speed machining," International Journal of Precision Engineering and Manufacturing, vol. 15, no. 8, pp. 1499-1506, 2014.

[4] Q. Wu, D.-P. Li, and Y.-D. Zhang, "Detecting milling deformation in 7075 aluminum alloy aeronautical monolithic components using the quasi-symmetric machining method," Metals, vol. 6, no. 4, article no. 80, 2016.

[5] K. P. S. Rana, "Fuzzy control of an electrodynamic shaker for automotive and aerospace vibration testing," Expert Systems with Applications, vol. 38, no. 9, pp. 11335-11346, 2011.

[6] M. Aykan and M. Çelik, "Vibration fatigue analysis and multiaxial effect in testing of aerospace structures," Mechanical Systems and Signal Processing, vol. 23, no. 3, pp. 897-907, 2009.

[7] Y.-S. Shih and G.-Y. Wu, "Effect of vibration on fatigue crack growth of an edge crack for a rectangular plate," International Journal of Fatigue, vol. 24, no. 5, pp. 557-566, 2002.

[8] P. Wang, H. Ni, R. Wang, Z. Li, and Y. Wang, "Experimental investigation of the effect of in-plane vibrations on friction for different materials," Tribology International, vol. 99, pp. 237-247, 2016.

[9] J. Muric-Nesic, P. Compston, N. Noble, and Z. H. Stachurski, "Effect of low frequency vibrations on void content in composite materials," Composites Part A: Applied Science and Manufacturing, vol. 40, no. 4, pp. 548-551, 2009.

[10] S. Biswas, S. Habib Alavi, and S. P. Harimkar, "Laser surface melting of Ti-6Al-4V under the influence of ultrasonic vibrations," Materials Letters, vol. 159, Article ID 19257, pp. 470-473, 2015.

[11] Z. Yao, G.-Y. Kim, L. Faidley, Q. Zou, D. Mei, and Z. Chen, "Effects of superimposed high-frequency vibration on deformation of aluminum in micro/meso-scale upsetting," Journal of Materials Processing Technology, vol. 212, no. 3, pp. 640-646, 2012.

[12] Y. Ishida, "Recent development of the passive vibration control method," Mechanical Systems and Signal Processing, vol. 29, pp. 2-18, 2012.

[13] T. P. Sales, D. A. Rade, and L. C. G. de Souza, "Passive vibration control of flexible spacecraft using shunted piezoelectric transducers," Aerospace Science and Technology, vol. 29, no. 1, pp. 403-412, 2013.

[14] Y. Zhang, Y. Zang, M. Li, Y. Wang, and W. Li, "Active-passive integrated vibration control for control moment gyros and its application to satellites," Journal of Sound and Vibration, vol. 394, pp. 1-14, 2017.

[15] J. S. Yang, "Hybrid active and passive control of a very large floating beam structure," Nonlinear Dynamics, vol. 87, no. 3, pp. 1835-1845, 2017.

[16] D. Gong, J. Zhou, and W. Sun, "Passive control of railway vehicle car body flexural vibration by means of underframe dampers," Journal of Mechanical Science and Technology, vol. 31, no. 2, pp. 555-564, 2017.

[17] A. Preumont, "Vibration Control of Active Structures: An Introduction," Meccanica, vol. 179, no. 2, p. 139, 1999.

[18] J. Plattenburg, J. T. Dreyer, and R. Singh, "Vibration control of a cylindrical shell with concurrent active piezoelectric patches and passive cardboard liner," Mechanical Systems and Signal Processing, vol. 91, pp. 422-437, 2017.
[19] T. Bailey and J. E. Ubbard, "Distributed piezoelectric-polymer active vibration control of a cantilever beam," Journal of Guidance, Control, and Dynamics, vol. 8, no. 5, pp. 605-611, 1985.

[20] A. Shimamoto and N. Kurosawa, "Active vibration control for truss bridge model by shrinkage force in shape memory alloy wire," Science, vol. 309, no. 5739, pp. 1338-1343, 2005.

[21] A. Baz, K. Imam, and J. McCoy, "Active vibration control of flexible beams using shape memory actuators," Journal of Sound and Vibration, vol. 140, no. 3, pp. 437-456, 1990.

[22] E. Omidi, S. N. Mahmoodi, and W. S. Shepard, "Vibration reduction in aerospace structures via an optimized modified positive velocity feedback control," Aerospace Science and Technology, vol. 45, article no. 3350, pp. 408-415, 2015.

[23] H. Y. Lin and C. Y. Wang, "Free vibration analysis of a hybrid beam composed of multiple elastic beam segments and elastic-supported rigid bodies," Journal of Marine Science and Technology, vol. 20, no. 5, pp. 525-533, 2012.

[24] H.-Y. Lin, "On the natural frequencies and mode shapes of a multi-span and multi-step beam carrying a number of concentrated elements," Structural Engineering and Mechanics, vol. 29, no. 5, pp. 531-550, 2008.

[25] H.-Y. Lin, "An exact solution for free vibrations of a nonuniform beam carrying multiple elastic-supported rigid bars," Structural Engineering and Mechanics, vol. 34, no. 4, pp. 399416, 2010.

[26] H. L. Dai, D. M. Zhao, J. J. Zou, and L. Wang, "Surface effect on the nonlinear forced vibration of cantilevered nanobeams," Physica E: Low-dimensional Systems and Nanostructures, vol. 80, pp. 25-30, 2016.

[27] S. H. Diaz Valdes and C. Soutis, "Delamination detection in composite laminates from variations of their modal characteristics," Journal of Sound and Vibration, vol. 228, no. 1, pp. 1-9, 1999.

[28] N. Ashwear and A. Eriksson, "Natural frequencies describe the pre-stress in tensegrity structures," Computers \& Structures, vol. 138, pp. 162-171, 2014.

[29] N. Vlajic, T. Fitzgerald, V. Nguyen, and B. Balachandran, "Geometrically exact planar beams with initial pre-stress and large curvature: Static configurations, natural frequencies, and mode shapes," International Journal of Solids and Structures, vol. 51, no. 19-20, pp. 3361-3371, 2014.

[30] M. Rabenda and B. Michalak, "Natural vibrations of prestressed thin functionally graded plates with dense system of ribs in two directions," Composite Structures, vol. 133, pp. 1016-1023, 2015.

[31] T. Murmu and S. C. Pradhan, "Small-scale effect on the vibration of nonuniform nanocantilever based on nonlocal elasticity theory," Physica E: Low-dimensional Systems and Nanostructures, vol. 41, no. 8, pp. 1451-1456, 2009.

[32] T. Murmu and S. C. Pradhan, "Vibration analysis of nanoplates under uniaxial prestressed conditions via nonlocal elasticity," Journal of Applied Physics, vol. 106, no. 10, Article ID 104301, 2009.

[33] B. Uğurlu, "A dual reciprocity boundary element solution method for the free vibration analysis of fluid-coupled Kirchhoff plates," Journal of Sound and Vibration, vol. 340, pp. 190210, 2015. 


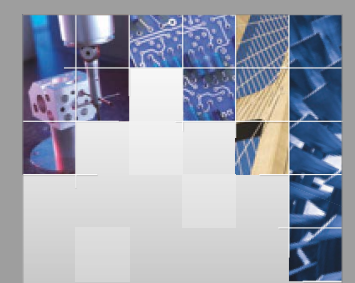

\section{Enfincering}
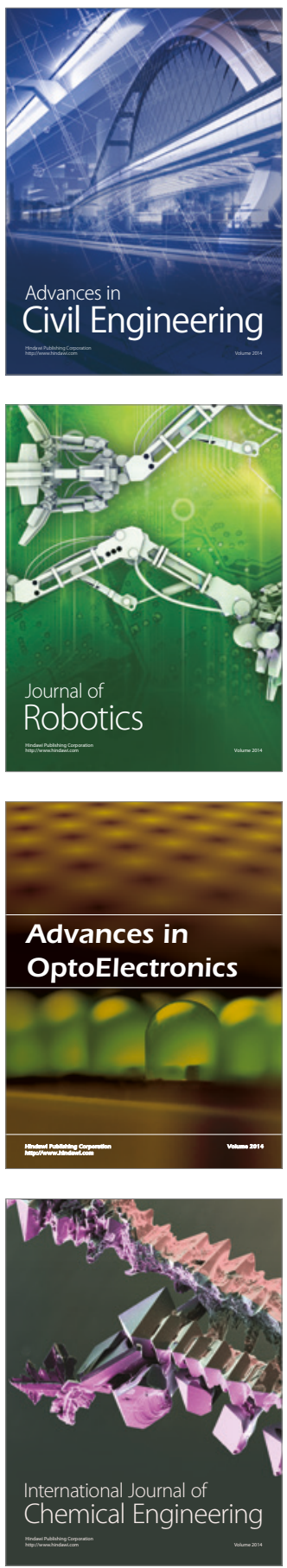

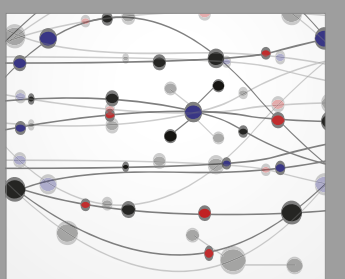

The Scientific World Journal

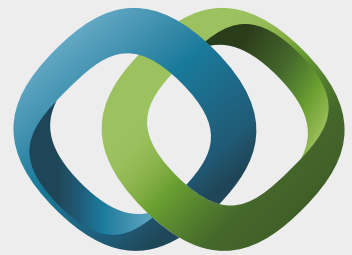

\section{Hindawi}

Submit your manuscripts at

https://www.hindawi.com
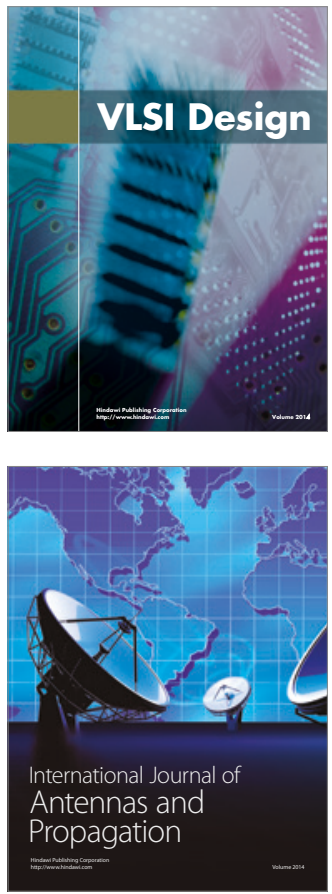

\section{Rotating}

Machinery
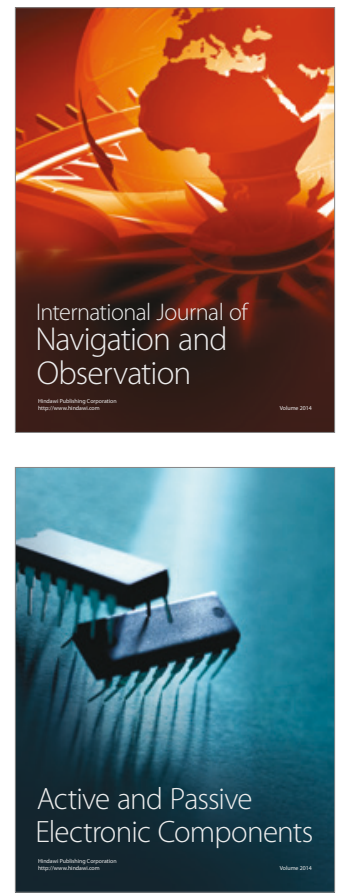
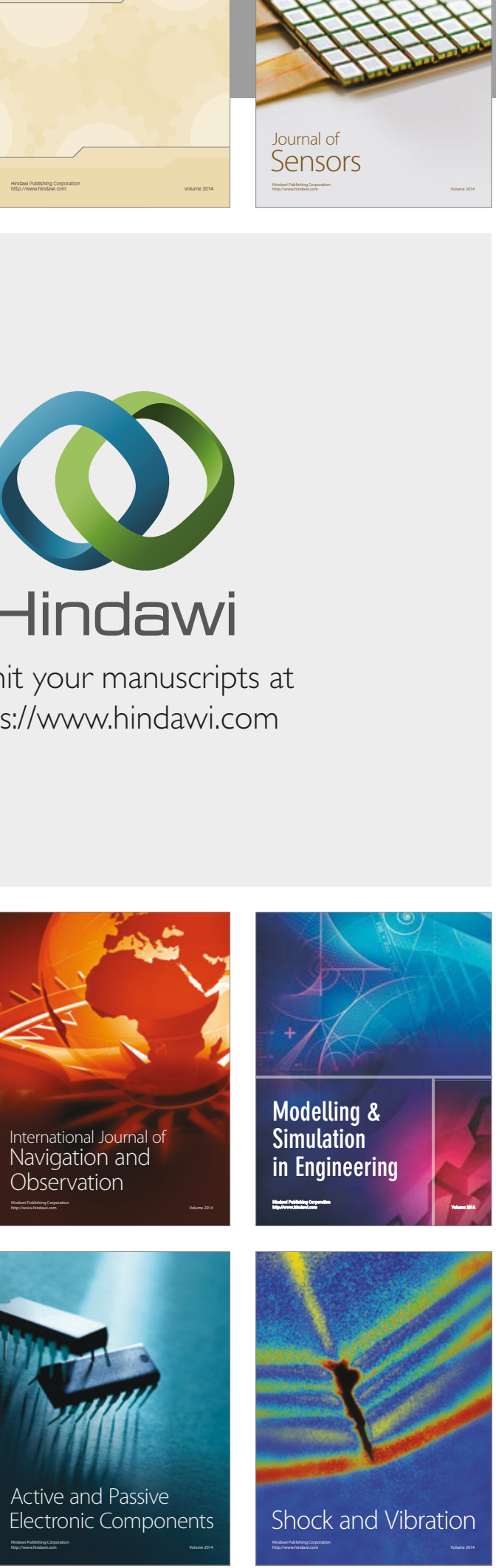
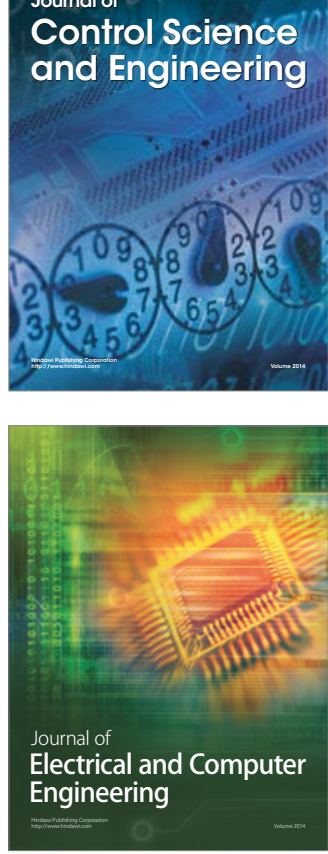

Distributed

Journal of

Control Science

and Engineering
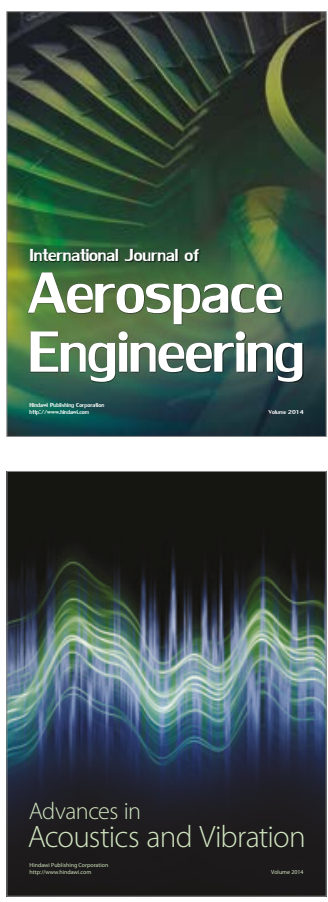

Sensor Networks 